\title{
The relationship between DNA structural variation and activities of $P$ elements in $P$ and Q strains of Drosophila melanogaster
}

\author{
EIJI NITASAKA* \& TSUNEYUKI YAMAZAKI \\ Department of Biology, Faculty of Science, Kyushu University, Fukuoka 812, Japan
}

\begin{abstract}
To characterize the relationship between $\mathrm{P}$ element activities and their structures, we cloned $\mathrm{P}$ elements from genomic libraries of three isogenic $\mathrm{P}$ and $\mathrm{Q}$ strains derived from natural populations in Japan. These $\mathrm{P}$ elements were mapped with Bam HI, AvalI and Pst I and were classified by their size. The majority of $\mathrm{P}$ elements cloned were classified as either complete or relatively small $\mathrm{P}$ elements rather than medium size. The numbers of full length $(2.9 \mathrm{~kb}) \mathrm{P}$ elements per haploid genome of NP280 (P), AK194 (weak P) and WY113 (Q) were at least four, five and one, respectively. However, the $2.9 \mathrm{~kb}$ P element of WY113 was thought to be defective since this strain has no transposase activity. In our previous work, we demonstrated that the ORF 3-deleted P element is essential for P cytotype determination in WY113. A similar P element also exists in NP280, and this may have an important role for $\mathrm{P}$ cytotype determination in this strain. Two and one copies of the KP element, a deletion derivative of the P element, were found in NP280 and AK194, respectively. One of four complete P elements in NP280 was fully sequenced, and the base sequence was completely identical to that of $\mathrm{p} \pi 25.1$ originally derived from the U.S.A. This result is consistent with the notion that these $\mathrm{P}$ elements have a relatively recent origin in Drosophila melanogaster.
\end{abstract}

Keywords: Drosophila melanogaster, horizontal transfer, P element, polymorphism, transposable elements.

\section{Introduction}

P elements, a class of transposable elements in Drosophila melanogaster, have been well studied for their biological features. They are responsible for $\mathrm{P}-\mathrm{M}$ hybrid dysgenesis which includes mutation, chromosomal rearrangement, sterility and male recombination. The transposition of $P$ elements occurs when a male of a $P$ strain containing active $P$ elements is mated with a female of an $\mathrm{M}$ strain containing no $\mathrm{P}$ element; but it does not occur in the reciprocal cross. This difference is explained by assuming a state, the $\mathrm{P}$ cytotype, in which a repressor is thought to exist. There are intermediate $\mathrm{P}$ activity strains called $\mathrm{Q}$ strains which do not induce gonadal (GD) sterility but have the $P$ cytotype (for review, see Engels, 1989).

$\mathrm{P}$ elements are known to be heterogeneous with respect to size and are classified into two major types (O'Hare \& Rubin, 1983). One type is called the

*Correspondence. complete (autonomous) P element which encodes the transposase catalysing transposition of $\mathrm{P}$ elements and is $2.9 \mathrm{~kb}$ in length. There are four exons, all of which are used to encode the transposase in germ cells (O'Hare \& Rubin, 1983; Laski et al., 1986). In somatic cells, the complete P element makes a protein only up to open reading frame 2 (ORF 2, exon 3 ) since the third intron is not spliced (Rio et al., 1986). This protein is thought to act as a repressor. Most Q strains have transposase activities, but we identified a $Q$ strain (WY113) lacking transposase activity, and showed that a $\mathrm{P}$ element having a deletion in ORF 3 (exon 4) is essential for the determination of the $\mathrm{P}$ cytotype in this strain (Nitasaka et al., 1987). It was also indicated that artificial P elements with the same structure had weak repression activities (Robertson \& Engels, 1989; Misra \& Rio, 1990). However the molecular mechanism of the development of the $\mathrm{P}$ cytotype is not yet understood completely.

The other major type of P element is called defective. These are deletion derivatives of the complete $\mathrm{P}$ 
elements. They are not completely inactive, and some are though to act as suppressors of $\mathrm{P}$ transposition. Two types of defective $\mathrm{P}$ elements have been characterized. One is a repressor-producing $\mathrm{P}$ element with a deletion in ORF 3 (see above). Another is a smaller $(1.15 \mathrm{~kb}) \mathrm{P}$ element, designated the KP element, which weakly suppresses hybrid dysgenesis and is found all over the world (Black et al., 1987).

The number of $\mathrm{P}$ elements per haploid genome varies from strain to strain. Strong $\mathrm{P}$ strains have 30-50 copies of $\mathrm{P}$ elements in their genome. The number of complete $P$ elements in a reference $P$ strain, $\pi 2$, was estimated as one-third of the total number of $P$ elements. Sequences of $\mathrm{P}$ elements from Drosophila melanogaster from diverse geographical locations are homogeneous and very similar to those of Drosophila willistoni (O'Hare \& Rubin, 1983; Iwano et al., 1984; Sakoyama et al., 1985; Black et al., 1987; Daniels et al., 1990; O'Hare et al., 1992). Moreover, the distribution of $\mathrm{P}$ elements is restricted in Drosophila melanogaster, and other closely related species have no $\mathrm{P}$ element sequence (Brookfield et al., 1984). Therefore, it is thought that $\mathrm{P}$ elements in Drosophila melanogaster were introduced from a species of the Drosophila willistoni group by horizonal transmission about 40 years ago (Daniels et al., 1990; Kidwell, 1992).

In this study, we analysed three $\mathrm{P}$ and $\mathrm{Q}$ strains derived from Japanese natural populations to study the relationship between the structure and activity of their $P$ elements. The base sequence of one of the complete $\mathrm{P}$ elements derived from a $\mathrm{P}$ strain was determined.

\section{Materials and methods}

\section{Fly stocks}

NP280 is an isogenic strain for the second chromosome which was derived from the Ishigaki island population (Okinawa prefecture, 1980). AK194 is an isogenic strain for the second and the third chromosomes which was derived from Akayu in 1977 (Yamagata prefecture, Yamazaki et al., 1984; Iwano et al., 1984). WY113 is an isogenic strain for the second chromosome which was derived from Osaka in 1978 (Mukai \& Yukuhiro, 1983; Nitasaka et al., 1987). This stock was originally described as a P-element-free strain by mistake (Iwano et al., 1984). The three strains above were constructed using P-element-free stocks carrying balancer chromosomes for the second (SM1, $C y / \operatorname{In}(2 L R) b w^{v /}$; for NP280 and WY113) and for the second and the third (SMI,Cy/In(2LR)bw $w^{v l} ; T M 3, S b$ Ser/Pr; for AK194). Female flies of these balancer stocks were mated with males from isofemale lines so that $\mathrm{P}$ element transposition might occur. Other strains used have been described by Nitasaka et al. (1987).
Most stocks were raised at $25^{\circ} \mathrm{C}$ except during GD sterility tests $\left(29^{\circ} \mathrm{C}\right.$ in the yeast-glucose medium).

\section{Tests for $P$ element activities}

To test the $\mathrm{P}$ element activity (transposase and repressor), we employed GD sterility and singed weak $\left(s n^{w}\right)$ hypermutability as indexes. Most of the methods are described by Kidwell (1986) and Nitasaka et al. (1987).

Repressor activity (or P cytotype) with $s n^{w}$ mutability was tested as follows. Five male flies of $C(1) D X$, $y \mathrm{f} / \mathrm{sn}^{\omega} ; \pi 2$ (Engels, 1979) were mated with five female flies of the strain to be tested, and $F_{1}$ virgin females were crossed with $w s n^{3} m$ males. $\mathrm{F}_{2}$ progeny were scored for the singed bristle phenotype and the frequency of $s n^{w}$ hypermutability was calculated by dividing the number of $s n^{e}$ by the total number of flies scored, $s n^{+}$flies were ignored for scoring since it is difficult to distinguish $s n^{+}$and flies carrying wild-type singed alleles $(+)$. In all cases, at least 1000 flies were scored.

\section{DNA techniques}

Most of the experimental methods for nucleic acids were described by Maniatis et al. (1982). Plasmids, p $\pi 25.7 \mathrm{dwc}$ (Nitasaka et al., 1987) or pPORF0123A (Nitasaka \& Yamazaki, 1988) carrying most of the P sequence (39-2882 bp) and no Drosophila sequence were used as probe DNA. $\lambda$ EMBL3 vector was used for the library construction and libraries were made using BamHI which does not cut in the P element. The obtained clones were analysed by the restriction enzymes BamHI, AvaII and PstI. AvaII cuts the full length $\mathrm{P}$ element four times, including two cuts in the right and left inverted repeats, so we were able to size the $\mathrm{P}$ elements. For more precise mapping, HindIII, EcoRI, XhoI, SalI and DdeI were also used. DdeI was used to test whether the given $\mathrm{P}$ element was a KP element (Black et al., 1987) or not. The $\lambda$ phage clones digested with $\mathrm{BamHI}$ were loaded on to a 0.8 per cent agarose gel, and those with other enzymes on a 1.5 per cent agarose gel. For Southern hybridization, filters were washed two times with $2 \times \mathrm{SSC}$ at room temperature for $5 \mathrm{~min}, 2 \times \mathrm{SSC}$ at $68^{\circ} \mathrm{C}$ for $15 \mathrm{~min}$ and $0.5 \times \mathrm{SSC}$ at $68^{\circ} \mathrm{C}$ for $15 \mathrm{~min}$.

A phage clone, $\lambda$ NP5. 2 containing a full length $P$ element derived from NP280, was digested with several restriction enzymes and ligated with pUC9. The nucleotide sequence was determined by the dideoxy method using Klenow enzyme (Sanger et al., 1980; M13 sequencing kit, Takara Shuzo). Denatured plasmid DNAs were used as templates instead of M13 phage DNA. The sequencing strategy and enzymes used are shown in Fig. 1. 


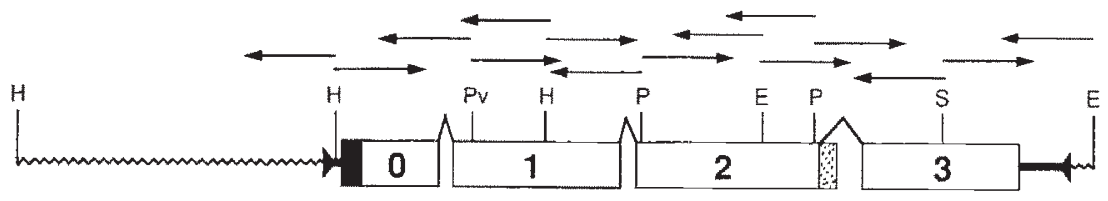

Fig. 1 Sequencing strategy for pNP5.2. Numbered boxes indicate $\mathrm{P}$ element exons. Open and filled boxes indicate the protein-coding and noncoding regions, respectively. Stippled box indicates the alternate coding region when the third intron is not spliced. Light, heavy and waved lines indicate the introns, nontranscribed region and Drosophila sequences, respectively. Triangles indicate the $31 \mathrm{bp}$ inverted repeat. $\mathrm{H}, \mathrm{E}, \mathrm{P}, \mathrm{Pv}$ and $\mathrm{S}$ represent the restriction sites of HindIII, EcoRI, PstI, $P v u I I$ and SaII, respectively. Each arrow indicates the direction and length of sequencing.

\section{In situ hybridization}

To test for the copy number of $\mathrm{P}$ elements in the strains tested, in situ hybridization was carried out. Females of the strains tested were crossed with males of a P-element-free stock, Canton-S, and $F_{1}$ larvae were used for slide preparation. Hybridization and detection were done using sulfonylated probe DNA and the second antibodies labelled with alkaline phosphatase (DNA Chemiprobe, Orgenics). pPORF0123A was used as a hybridization probe. Before labelling, this plasmid was digested with HindIII, EcoRI and SalI to ease the hybridization. At least five slides per strain were scored for testing the copy number of $\mathrm{P}$ elements.

\section{Results}

\section{$P$ element activity and cytotype of strains used}

We selected three isogenic strains, NP280, AK194 and WY113 derived from Japanese natural populations to investigate the relationship between $\mathrm{P}$ element activity and structure. Transposase and repressor (cytotype) activities of these strains can be tested by GD sterility and $s n^{w}$ hypermutability tests (Kidwell et al., 1977; Engels, 1979, 1984). NP280, AK194 (Yamazaki et al., 1984) and WY113 (Nitasaka et al., 1987) were characterized as a strong $\mathrm{P}$, a weak $\mathrm{P}$ and a $\mathrm{Q}$ strain, respectively, by GD sterility test. These results are summarized in Table 1. NP280 was classified as a strong P strain by the GD sterility test but showed a relatively low level of $s n^{w}$ hypermutability. A similar strain was reported by Engels (1984). In the $s n^{w}$ hypermutability tests for transposase activity, we tested the effect of only the second and the third chromosomes, but in the GD sterility tests we tested for all chromosomes. However, this may not be the cause of the disagreement between GD sterility and $s n^{w}$ hypermuta- bility results because all three strains used have no $\mathrm{P}$ element or few $\mathrm{P}$ elements on $\mathrm{X}$ chromosomes (see below). All $\mathrm{P}$ elements on the $\mathrm{X}$ chromosome seem to be defective $\mathrm{P}$ elements since our preliminary results using the $s n^{w}$ hypermutability test showed that none of the $\mathrm{X}$ chromosomes of these strains have transposase activity (data not shown). Another interesting result is that WY113 had no transposase activity, but had a strong $\mathrm{P}$ cytotype. Therefore, the defective $\mathrm{P}$ element(s) of this strain determines the $\mathrm{P}$ cytotype (Nitasaka et al., 1987).

\section{Copy number of $P$ elements}

All strains used are isogenic for the second (NP280 and WY113) or both the second and the third (AK194) chromosomes. Thus their X chromosomes were derived from balancer stocks which have no $\mathrm{P}$ elements ( $M$ strain). We tested the copy number of $P$ elements by in situ hybridization and genomic Southern blot analysis. There were no (WY113) or few P elements (NP280 and AK194) on the X chromosomes. These P elements were thought to be transposed from the autosomes to the $\mathrm{X}$ chromosomes when their chromosomes were extracted. The copy numbers of $\mathrm{P}$ elements per haploid genome in NP280, AK194 and WY113 were approximately 35, 25 and 15, respectively (Table 1).

\section{Cloning and mapping of $P$ elements}

To characterize the structure of P elements, we made genomic libraries of NP280, AK194 and WY113. Genomic DNA of each strain was partially digested with $B a m \mathrm{HI}$, and was ligated with the arms of the $\lambda$ EMBL3 vector (Frischauf et al., 1983). Intact $P$ elements can be cloned using Bam $\mathrm{HI}$ since complete $\mathrm{P}$ elements have no site for BamHI digestion. We made 
Table $1 \mathrm{P}$ element activity and copy number in strains of Drosophila melanogaster

\begin{tabular}{lcrrrrr}
\hline & & \multicolumn{2}{c}{ Transposase activity } & & \multicolumn{2}{c}{ Repressor activity } \\
\cline { 3 - 4 } \cline { 6 - 7 } Strains & Copy number & GD $(\%)^{*}$ & $s n^{\omega}(\%) \dagger$ & & GD $(\%)^{*}$ & $s n^{\omega}(\%) \neq$ \\
\hline NP280 & $30-35$ & 100.0 & 8.1 & & 0.0 & 0.40 \\
AK194 & $20-25$ & 14.6 & 19.3 & & 0.0 & 0.69 \\
WY113 & $12-15$ & 0.0 & 0.0 & & 0.0 & 0.0 \\
\hline
\end{tabular}

${ }^{*}$ GD sterility $=($ dysgenic ovaries $/($ dissected females $\times 2)) \times 100$.

$\dagger s n^{w}$ hypermutability $=\left(\left(s n^{+}+s n^{e}\right) /\left(s n^{+}+s n^{e}+s n^{w}\right)\right) \times 100$.

$\neq s n^{w}$ hypermutability $=\left(s n^{e} / s n^{w}\right) \times 100$.

libraries containing approximate $10^{7}$ phages per $\mu \mathrm{g}$ DNA, and this number was sufficient for covering the whole genome of Drosophila melanogaster. These unamplified libraries were screened with a whole $\mathrm{P}$ element probe without flanking genomic sequences ( $\mathrm{p} \pi 25.7 \mathrm{dwc} ;$ Nitasaka et al., 1987). We selected 50, 43 and 27 positively hybridizing phages at random from the libraries of NP280, AK194 and WY113, respectively. DNA from these phages was digested with BamHI to cut off the vector sequences, and the sizes of the BamHI fragments containing $\mathrm{P}$ elements were determined by Southern blot analysis. These sizes are specific for their insertional sites (or chromosomal locations). Therefore $\mathrm{P}$ clones which have fragments with the same size were thought to derive from the same genomic positions.

AvaII restriction enzyme has four restriction sites in a complete $P$ element and two of them are located in the inverted repeats (IRs). Thus we can determine the precise size of a given $\mathrm{P}$ element. Pst I cuts the complete $P$ element twice and one site is located near the junction of exon 1-2 and another site near the junction of exon 2-3. For the above reasons, $\mathrm{P}$ clones of NP280 and AK194 were mapped with AvaII and PstI. All clones were tested as to whether they derived from independent genomic positions by restriction fragment sizing with Bam HI, AvaII and PstI. P clones derived from WY113 were mapped more precisely using the additional restriction enzymes HindIII, XhoI, EcoRI and Sall.

We were able to isolate $P$ elements in 27,18 and 9 independent insertional sites from NP280, AK194 and WY113 libraries, respectively. These maps are shown in Fig. 2. These numbers roughly corresponded to twothirds to three-quarters of the total number of $\mathrm{P}$ elements determined by in situ hybridization and Southern blot analysis. The copy numbers of the full length P elements $(2.9 \mathrm{~kb})$ for NP280, AK194 and WY113 were at least four, five and one, respectively. However, the $2.9 \mathrm{~kb}$ P element in WY113 is thought to be defective since this strain has no transposase activity. In our previous work, we demonstrated that the ORF 3 deleted $\mathrm{P}$ element is essential for $\mathrm{P}$ cytotype determination in WY113 (Nitasaka et al., 1987). A similar P element also existed in NP280, and it may have an important role for $\mathrm{P}$ cytotype determination in this strain. An interesting feature is that $P$ elements with the same sizes existed in several chromosomal positions in NP280 and AK194 (1.2, 1.1, 1.0 and $0.6 \mathrm{~kb}$ P elements in NP280; 1.3, 1.0,0.9 and 0.7 $\mathrm{kb}$ in AK194).

We could not isolate $\mathrm{P}$ elements on BamHI fragments over $20 \mathrm{~kb}$, which exceed the cloning capacity of the $\lambda$ phage vector. Genomic DNAs of these strains were analysed by Southern blotting using a whole $P$ element probe and an ORF 2 probe $(\mathrm{a} 0.7 \mathrm{~kb}$ fragment digested with Pst $\mathbf{I}$ ) after Bam HI digestion to examine the copy number of $\mathrm{P}$ elements. There were a few Bam HI fragments containing P elements over $20 \mathrm{~kb}$ in NP280, AK194 (two small P elements) and WY113 (one large and one small $\mathrm{P}$ element on the second chromosome). We did not examine the structure of these P elements on the Bam HI fragments over $20 \mathrm{~kb}$.

Black et al. (1987) reported that defective $\mathrm{P}$ elements, designated as KP elements, invaded all over the world and somewhat suppressed the hybrid dysgenesis. The size of the KP element is $1154 \mathrm{bp}$, and if it is digested with DdeI and AvaII, one $423 \mathrm{bp}$ and two $478 \mathrm{bp}$ and $629 \mathrm{bp}$ internal fragments appear, respectively. All $\mathrm{P}$ element clones ranging from 1.0 to $1.3 \mathrm{~kb}$ of the three strains were tested by $D d e \mathrm{I}$ and AvaII. P clones from two different genomic positions in NP280, and from a single genomic position in AK194, had fragments of the same length as the KP element (indicated by * in Fig. 2). Ito et al. (1989) also indicated the presence of KP elements in Japan, by sequencing. 


\section{Nucleotide sequence of a complete $P$ element in NP280}

To evaluate the difference between complete $\mathrm{P}$ elements from NP280 and $\mathrm{p} \pi 25.1$ derived from a $\mathrm{P}$ strain, $\pi 2$ (U.S.A. population, Engels \& Preston, 1979; O'Hare \& Rubin, 1983), one of the complete P elements of NP280 (pNP5.2) was fully sequenced (Fig. 1). There was no nucleotide difference between

(a)

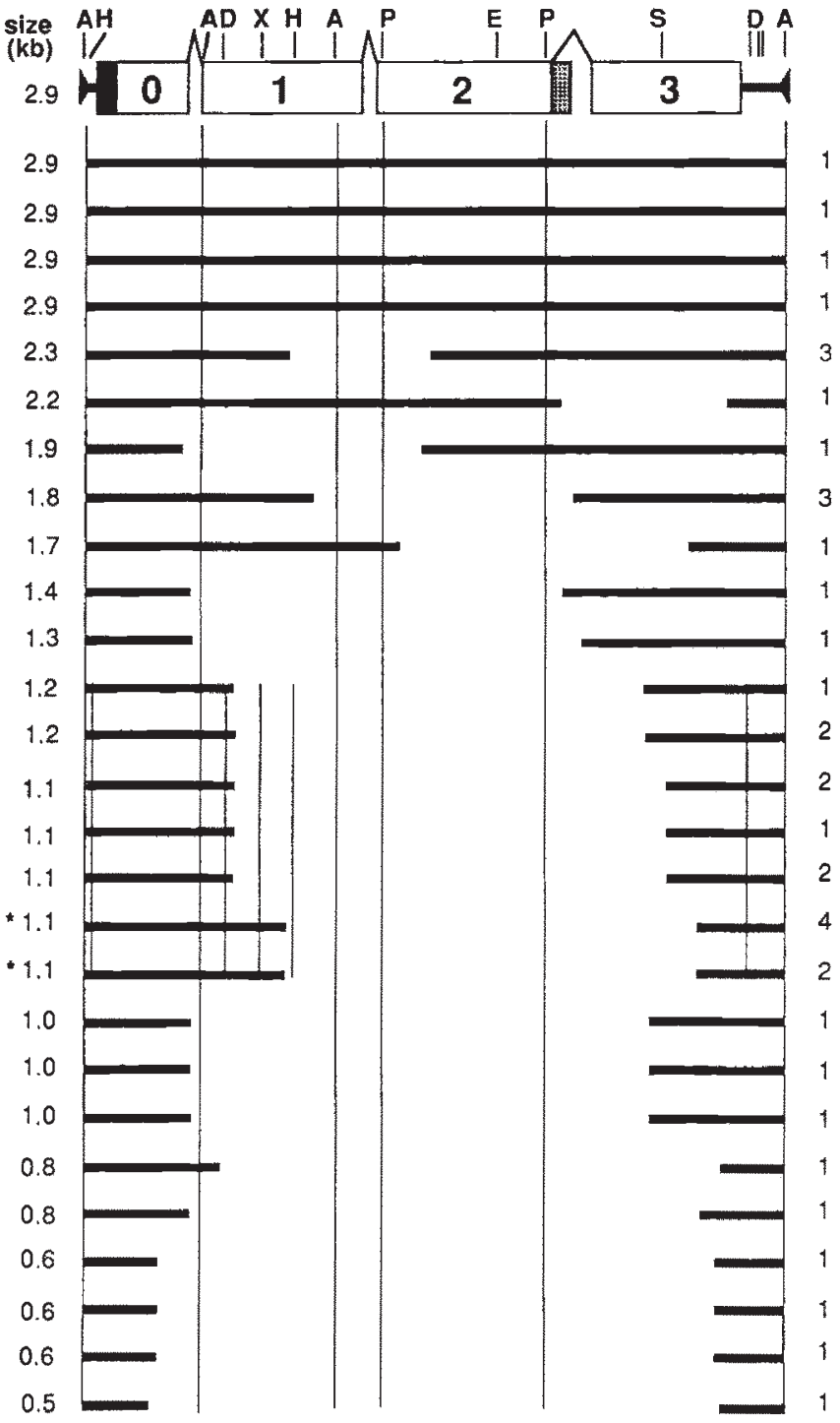

pNP5.2 and $\mathrm{p} \pi 25.1$ throughout the whole 2907 bases. The duplicated eight nucleotides of pNP5.2 were GATCGATG and only two of the eight bases agreed with the consensus sequence GGCCAGAC determined by O'Hare \& Rubin (1983).

(b)

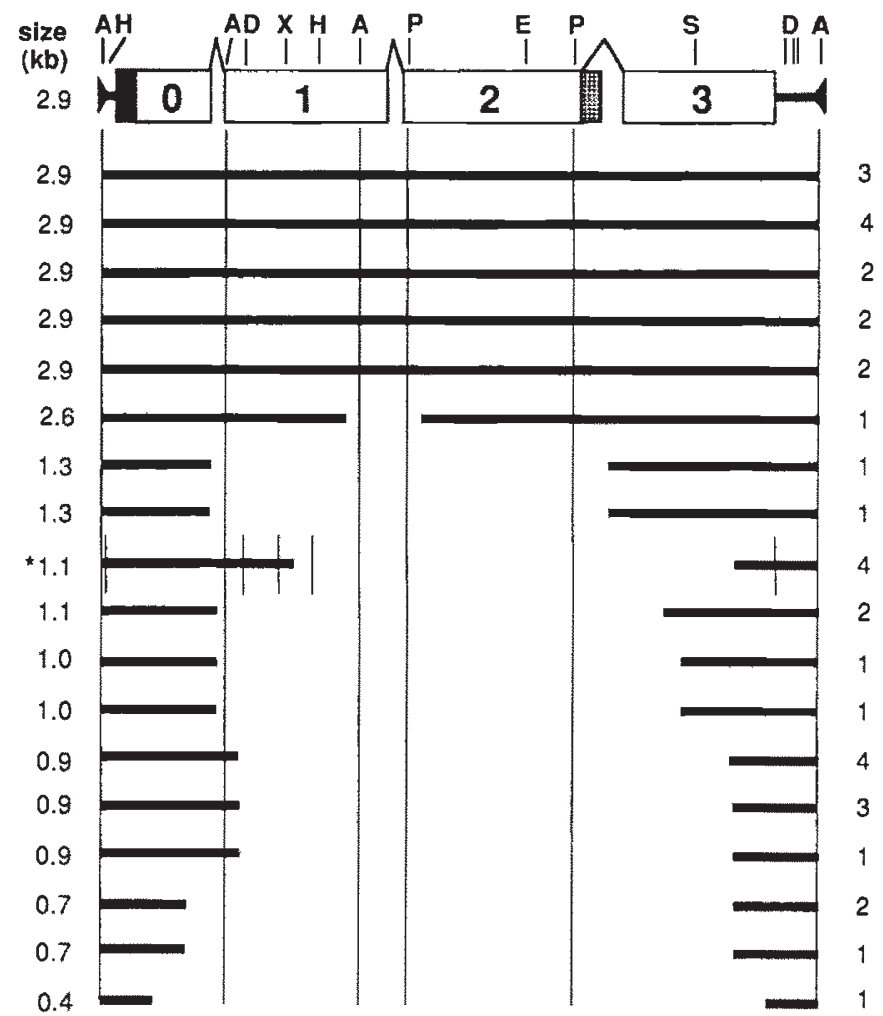

(c)

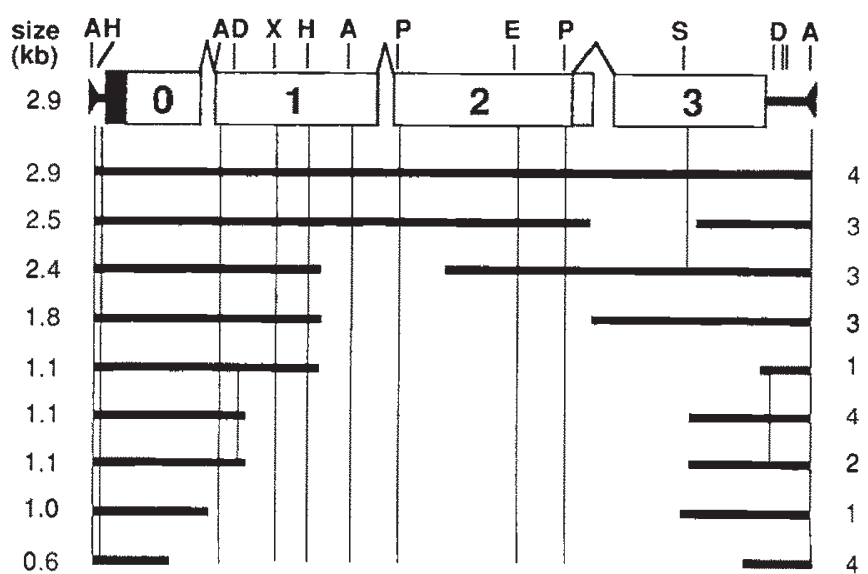

Fig. 2 Restriction maps of $P$ elements derived from $P$ and $Q$ strains. The numbers at the left and right are total lengths of $P$ elements and the number of clones independently isolated, respectively. The upper figure shows the structure of a complete $P$ element. A, D and X indicate the restriction sites of AvaII, DdeI and XhoI, respectively. Other sites are the same as in Fig. 1. Vertical lines represent restriction enzymes used for crossing clones. Horizontal lines indicate the approximate structure of each clone. (a) Restriction maps of P elements derived from NP280. (b) Restriction maps of P elements derived from AK194. (c) Restriction maps of $\mathbf{P}$ elements derived from WY113. 


\section{Discussion}

We could isolate two-thirds to three-quarters of the total number of $\mathrm{P}$ elements in $\mathrm{P}$ and $\mathrm{Q}$ strains. It appears that the copy number is roughly correlated with the $\mathrm{P}$ element activity tested by GD sterility. However, considering the copy number of complete Ps and the transposase activity measured by $s n^{\omega}$ hypermutability in NP280 and AK194, there is no clear correlation between the above two parameters. In particular, NP280 is classified as a P strain by the GD sterility test, but showed relatively low $s n^{w}$ mutability. We think that the $s n^{w}$ mutability test is more sensitive regarding transposase activity than GD sterility, since the former is P-specific and is mainly affected by transposase. We suppose that the absence of this correlation is partly due to the titration of transposase by many defective $P$ elements (Simmons \& Bucholz, 1985) and the effect of the ORF 3-deleted P element in NP280.

The copy numbers of $2.9 \mathrm{~kb}$ P elements were at least four, five and one in NP280, AK194 and WY113, respectively. Though WY113 had a $2.9 \mathrm{~kb}$ P element, it must be inactive because this strain had no transposase activity (Nitasaka et al., 1987). Since we could isolate two-thirds to three-quarters of the total $\mathrm{P}$ elements, the actual number of complete $\mathrm{P}$ elements per haploid genome may be calculated as follows: in $\mathrm{NP} 280,4 \times 35 / 27=5.2$; in AK $194,5 \times 25 / 18=6.9$. In the case of a strong P strain $\pi 2$, in which the numbers of $\mathrm{P}$ elements are approximately 30-50, seven out of $26 \mathrm{P}$ elements were complete P elements (O'Hare \& Rubin, 1983; O'Hare et al., 1992). The ratio of complete $\mathrm{P}$ elements to total P elements is lower in NP280 and WY113. These rates may correlate with $s n^{w}$ hypermutability.

All strains tested had strong $P$ cytotypes judging from repressor activity tests using GD sterility and $s \eta^{w}$ hypermutability. We showed that the ORF 3-deleted $P$ element was necessary for determination of the P cytotype in WY113 (Nitasaka et al., 1987). The same type of P element also existed in NP280 but not in AK194. It seems that the ORF 3-deleted $\mathrm{P}$ element has a role in determination of $\mathrm{P}$ cytotype in NP280. The KP element which is a deletion derivative of a $\mathrm{P}$ element is $1154 \mathrm{bp}$ in length. This element weakly suppresses the transposition of $\mathrm{P}$ elements and was found in many strains derived from all over the world (Black et al., 1987). There are two and one KP elements with similar length and maps in NP280 and AK194, respectively. On the other hand, we could not detect any KP elements in WY113. It seems that KP elements have no role in cytotype determination in WY113. In the case of AK194, some complete and/or small $\mathrm{P}$ elements (especially KP elements) may determine the strong $\mathrm{P}$ cytotype in this strain.
Fig. 3 Distribution of total lengths of $P$ elements vs. copy number.

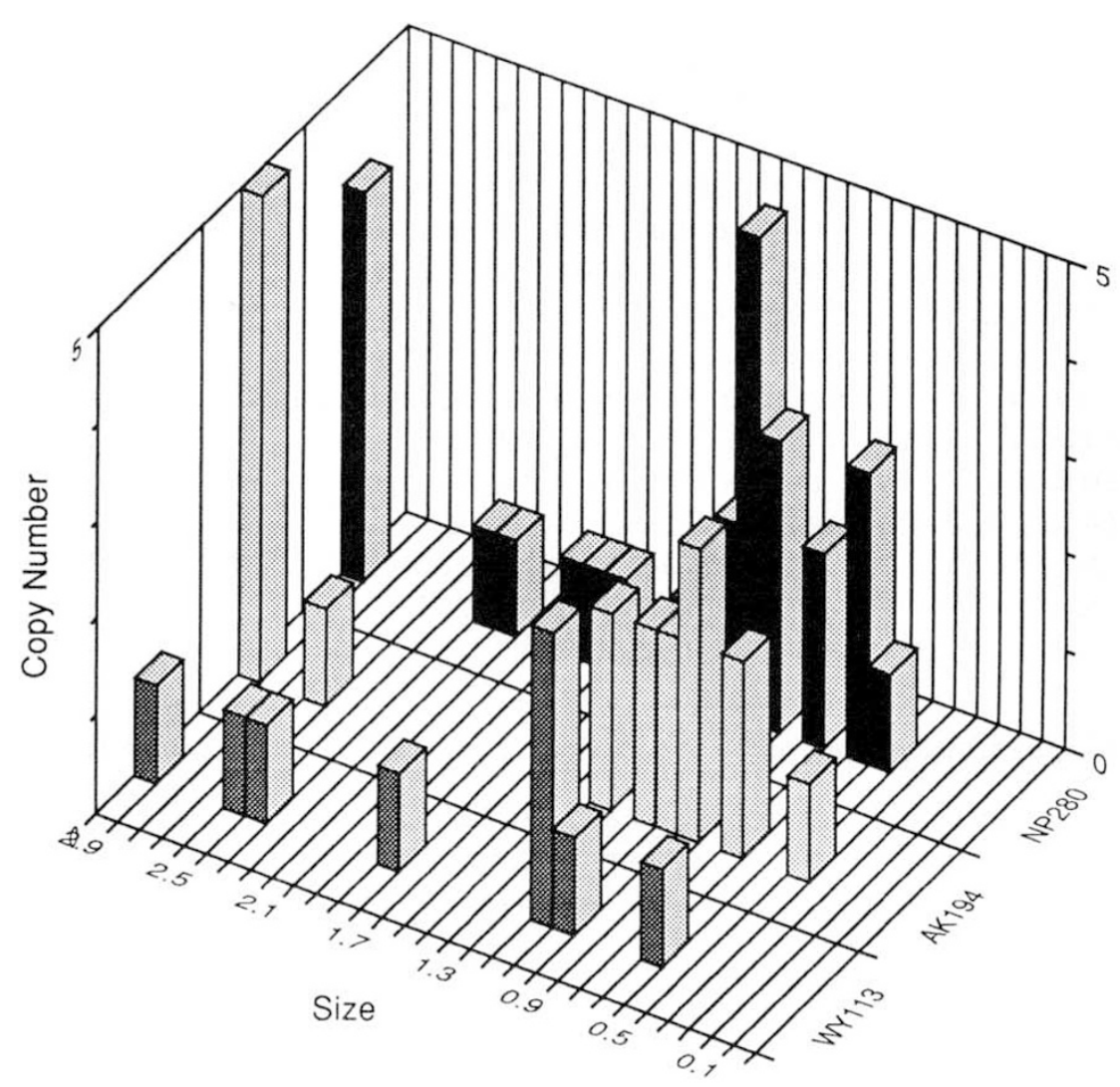


As far as the lengths of $\mathrm{P}$ elements are concerned, most of the $\mathrm{P}$ elements were classified as complete or relatively small $(<1.3 \mathrm{~kb})$, and as $\mathrm{P}$ elements with medium size, though these were rare. There were small $\mathrm{P}$ elements with the same length in different genomic positions (e.g. $1.1 \mathrm{~kb}$ elements in NP280 and $0.9 \mathrm{~kb}$ elements in AK194). These results are consistent with the notion that the small $\mathrm{P}$ elements multiply more easily than large $\mathrm{P}$ elements and transpose to different genomic positions, as suggested in the case of $\mathrm{KP}$ elements. The smallest P element we cloned was $0.4 \mathrm{~kb}$ from AK194 in spite of our cloning system being able to detect smaller P elements. It is unlikely that we only selected $\lambda$ clones with strong signals. It has been suggested that at least $138 \mathrm{bp}$ of $5^{\prime}$ sequence and at least $150 \mathrm{bp}$ of $3^{\prime}$ sequence are needed for transposition (O'Hare \& Rubin, 1983; Mullins et al., 1989), so small P elements cannot transpose and multiply. Histograms of $\mathrm{P}$ element sizes for each strain are summarized in Fig. 3.

The target sequence of $\mathrm{P}$ element insertion of pNP5.2 was quite different from the consensus sequence determined by O'Hare \& Rubin (1983). We consider that $\mathrm{P}$ elements recognize not only the eight target sequences but also other sequences such as the secondary structure of DNA.

It is clear that all AvaII and PstI sites were conserved in the P elements analysed (Fig. 2). Moreover no nucleotide difference was found between the pNP5.2 from a Japanese population and the $\mathrm{p} \pi 25.1$ (O'Hare \& Rubin, 1983) from the U.S. population throughout the whole 2907 bases. This observation may be because of to the relatively recent history of $\mathrm{P}$ elements in Drosophila melanogaster. The same result was also reported by several researchers using $\mathrm{P}$ elements derived from diverse geographical locations (O'Hare \& Rubin, 1983; Iwano et al., 1984; Sakoyama et al., 1985; Black et al., 1987). In particular, the sequence of a $\mathrm{P}$ element from Drosophila willistoni was identical to that of $\mathrm{p} \pi 25.1$, with a single nucleotide exception. Thus, it is now thought that $\mathbf{P}$ elements in Drosophila melanogaster were introduced from a species of the Drosophila willistoni group by horizontal transmission about 40 years ago (Daniels et al., 1990). Our results also support this hypothesis.

\section{Acknowledgements}

We are grateful to Dr Y. Matsuo and Mr M. Iwano for kind technical advice and communication of unpublished results, respectively. This work was supported by a Grant-in-Aid for Priority Area No. 62124047 from the Ministry of Education, Science and Culture of Japan.

\section{References}

BLACK, M. D., JACKSON, M. S., KIDWELL, M. G. AND DOVER, G. A. 1987. KP elements repress P-induced hybrid dysgenesis in Drosophila melanogaster EMBO J., 6, 4125-4135.

BROOKFIELD, J. F. Y., MONTGOMERY, E. AND LANGLEY, C. H. 1984. Apparent absence of transposable elements related to the P elements of D. melanogaster in other species of Drosophila. Nature, 310, 330-332.

DANIELS, S. B., PETERSON, K. R., STRAUSBAUGH, L. D., KIDWELl, M. G. AND CHOVNICK, A. 1990. Evidence for horizontal transmission of the $\mathbf{P}$ transposable element between Drosophila species. Genetics, 124, 339-355.

ENGELS, W. R. 1979. Extrachromosomal control of mutability in Drosophila melanogaster. Proc. Natl. Acad. Sci. U.S.A., 76, 4011-4015.

ENGELS, W. R. 1984. A trans-acting product needed for P factor transposition in Drosophila. Science, 226, 1194-1196.

ENGELS, w. R. 1989. P elements in Drosophila. In: Berg, D. and Howe, M. (eds) Mobile DNA, pp. 437-484. ASM Publications, Washington, DC.

ENGELS, W. R. AND PRESTON, C. R. 1979. Hybrid dysgenesis in Drosophila melanogaster: the biology of female and male sterility. Genetics, 92, 161-174.

FRISCHAUF, A. M., LEHRACH, H., POUSTKA, A. AND MURRAY, N. 1983. Lambda replacement vector carrying polylinker sequences. J. Mol. Biol., 170, 827-842.

ITO, M., IWABUCHI, M., YOSHIDA, K. AND HORI, S. H. 1989. Four tandem defective $\mathrm{P}$ elements associated with positive regulation of the Drosophila melanogaster glucose-6phosphate dehydrogenase gene. Biochem. Genet., 27, 699-718.

IWANO, M., HATTORI, K., SAIGO, K., MATUO, Y., MUKAI, T. AND YAMAZAKI, T. 1984. Cloning of $\mathrm{P}$ elements from $\mathrm{P}$ and $\mathrm{Q}$ strains in natural populations of Drosophila melanogaster in Japan. Jap. J. Genet., 59, 403-409.

KIDWELL, M. G. 1986. P-M mutagenesis. In: Roberts, J. A. (ed.) Drosophila, a Practical Approach, pp. 59-81. IRL Press, Oxford.

KIDWELL, M. G. 1992. Horizontal transfer of P elements and other short inverted repeat transposons. Genetica, 86, 275-286.

KIDWELL, M. G., KIDWELL, J. F. AND SVED, J. A. 1977. Hybrid dysgenesis in Drosophila melanogaster: a syndrome of aberrant traits including mutation, sterility and male recombination. Genetics, 86, 813-833.

LASKI, F, A., RIO, D. C. AND RUBIN, G. M. 1986. Tissue specificity of Drosophila $\mathbf{P}$ element transposition is regulated at the level of the mRNA splicing. Cell, 44, 7-19.

MANIATIS, T., FRITSCH, E. F. AND SAMBROOK, J. 1982. Molecular Cloning: A Laboratory Manual. Cold Spring Harbor Laboratory, New York.

MISRA, S. AND RIO, D. C. 1990. Cytotype control of Drosophila $\mathbf{P}$ element transposition: the $66 \mathrm{kd}$ protein is a repressor of transposase activity. Cell, 62, 269-284.

MUKAI, T. AND YUKUHIRO, K. 1983. An extremely high rate of deleterious viability mutations in Drosophila possibly caused by transposons in the non-coding region. Proc. Jap. Acad., 59(B), 316-319. 
MULLINS, M. C., RIO, D. C. AND RUBIN, G. M. 1989. Cis-acting DNA sequence requirements for $\mathrm{P}$-element transposition. Genes Devel., 3, 729-738.

NITASAKA, E., MUKAl, T. AND yAMAZAKI, T. 1987. Repressor of $P$ elements in Drosophila melanogaster: cytotype determination by a defective $P$ element carrying only open reading frames 0 through 2. Proc. Natl. Acad. Sci. U.S.A., 84, 7605-7608.

NITASAKA, E. AND YAMAZAKI, T. 1988. Excision of one of two defective $P$ elements as the cause of alternate mutational events $\left(s n^{+}\right.$and $\left.s n^{e}\right)$ of the singed bristle allele $s n^{w}$ in Drosophila melanogaster. Jap. J. Genet., 63, 303-312.

O'HARE, K. AND RUBIN, G. M. 1983. Structure of P transposable elements and their sites of insertion and excision in the Drosophila melanogaster genome. Cell, 34, 25-35.

O'HARE, K., DRIVER, A., McGRATH, S. AND JOHNSON-SCHILTZ, D. 1992. Distribution and structure of cloned $\mathbf{P}$ elements from the Drosophila melanogaster $\mathrm{P}$ strain $\pi 2$. Genet. Res., 60, 33-41.

RIO, D. C., LASKI, F. A. AND RUBIN, G. M. 1986. Identification and immunochemical analysis of biologically active Drosophila $\mathrm{P}$ element transposase. Cell, 44, 21-32.
ROBERTSON, H. M. AND ENGELS, w. R. 1989. Modified P elements mimic the $\mathbf{P}$ cytotype in Drosophila melanogaster. Genetics, 123, 815-824.

SAKOYAMA, Y., TODO, T., ISHIWA-CHIGUSA, S., HONJO, T. AND KONDO, $\mathrm{S}$ 1985. Structures of defective $\mathbf{P}$ transposable elements prevalent in natural $\mathrm{Q}$ and $\mathrm{Q}$-derived $\mathrm{M}$ strains of Drosophila melanogaster. Proc. Natl. Acad. Sci. U.S.A., 82, 6236-6239.

SANGER, F., COULSON, A. R., BARRELL, B. G., SMTTH, A. J. H. AND ROE, B. A. 1980 . Cloning in single-stranded bacteriophage as an aid to rapid DNA sequencing. J. Mol. Biol., 143, 161-178.

SIMMONS, M. J. AND BUCHOLZ, L. M. 1985. Transposase titration in Drosophila melanogaster: a model of cytotype in the $P$ $M$ system of hybrid dysgenesis. Proc. Natl. Acad. Sci. U.S.A., 82, 8119-8123.

YAMAZAKI, T., MATSUO, Y., INOUE, Y. AND MATSUO, Y. 1984. Genetic analysis of natural populations of Drosophila melanogaster in Japan. I. The amount of protein polymorphisms, lethal genes, sterility genes, inversion polymorphisms and linkage disequilibrium. Jap. J. Genet., 59 , 33-49. 